\title{
Preferences of the peripheral olfactory system of Western Flower Thrips, Frankliniella occidentalis towards stereoisomers of common plant volatiles
}

\author{
Zayed S. Abdullah • Tariq M. Butt
}

Received: 16 July 2014/ Accepted: 1 October 2014 / Published online: 18 October 2014

(C) The Author(s) 2014. This article is published with open access at Springerlink.com

\begin{abstract}
Stereochemistry plays a significant role in structure-activity relationships of messenger chemicals. The ability to distinguish between enantiomers and geometric isomers, however, may be limited to certain stereoisomeric substances, depending on the receiver. In this study, we assessed the preference of the peripheral olfactometry system of Western Flower Thrips, F. occidentalis towards ubiquitously expressed host compounds, with a goal of establishing whether particular stereoisomers enhance host odour recognition. We demonstrate that the peripheral olfactory system of a highly polyphagous thysanopteran insect has evolved to become highly sensitive to a type of green leaf volatile, which is highly ubiquitous in the plant kingdom. We show that there is a significantly greater antennal response to the cis isomer, more so than the isomerisation by-product trans-3-hexen-1-ol. We demonstrate that the antennae of a highly polyphagous insect are capable of detecting common plant secondary metabolites in both enantiomeric forms.
\end{abstract}

Keywords Enantioselectivity · Electroantennogram · Frankliniella occidentalis · Olfaction · Polyphagous · Stereoisomers

Handling Editor: Michael Heethoff.

Electronic supplementary material The online version of this article (doi:10.1007/s00049-014-0173-2) contains supplementary material, which is available to authorized users.

Z. S. Abdullah $(\bowtie) \cdot$ T. M. Butt

Department of Biosciences, Swansea University, Singleton Park,

Swansea SA2 8PP, UK

e-mail: 489458@swansea.ac.uk

\section{Introduction}

Insects utilize a peripheral olfactory system to sense chemical cues in the environment that are associated with mate and host recognition, as well as to avoid danger (Dethier 1947). Efficient localization of suitable hosts is paramount to species survival. Contrastingly, inability to identify unpalatable or toxic non-hosts severely decreases fitness. Sensilla situated on the insect antennae house olfactory receptor neurons (ORNs) activated by various chemical ligands from the external environment. The signals produced from these ORNs along with other sensory inputs travel to various processing regions of the brain, and a subsequent behavioural response then follows (Distler and Boeckh 1996; Galizia and Rössler 2010; Tolbert and Hildebrand 1981). Elucidating the nature of chemical ligand/receptor interactions at the antennal level is the first step in understanding the complex mechanisms of how insects process olfactory cues. Such understanding is important for the development of novel integrated pest management strategies that incorporate efficient use of semiochemicals, as well as discerning the vast use of olfactory cues in ecological systems.

Stereochemistry plays a significant role in structureactivity relationships of messenger chemicals (Mori 2002). The ability to distinguish between enantiomers and geometric isomers, however, may be limited to certain stereoisomeric substances, dependent on the receiver (Laska and Teubner 1999; Laska and Galizia 2001; Linster et al. 2001). In certain species of insects, chirality is important for the specificity of ORNs tuned to components of pheromones (Tumlinson et al. 1977; Leal 1996; Mori 1998). Various studies have determined enantiospecificity of the antennae responding to non-pheromonal odour compounds in insects of the orders Coleoptera, Lepidoptera 
and Hymenoptera (Wibe et al. 1998; Schorkopf et al. 2011; Stranden et al. 2002, 2003; Park et al. 2001). To our knowledge, however, no study has used antennal recordings to determine enantiomeric preferences in highly polyphagous thysanopteran insect pests towards common plant volatiles.

Western Flower Thrips, Frankliniella occidentalis P. (Thysanoptera: Thripidae), is a major agricultural and horticulture pest worldwide (Kirk 2002; Kirk and Terry 2003). The species has a broad host range of more than 500 species in 50 plant families (Yudin et al. 1986), making it a useful model for studies on polyphagous insect chemoreception. As a pest species, it causes damage and spoilage to a vast number of economically important plants through feeding, oviposition and spread of various plant diseases (Morse and Hoddle 2006). Given the species' cryptic nature and small size, thrips can often remain undetected through quarantine control measures; hence, their spread has been facilitated by the increase in international plant movement (Kiritani 2001). As with most insect pests that have rapid generation periods and produce copious amounts of offspring, a major concern is the rapid development of resistance to conventional chemical pesticides (Bielza et al. 2007; Bielza 2008). This problem is accentuated by the fact that many pesticides have been withdrawn in the EU (EEC Directive 2009/128/EC), creating a need to develop alternative control methods.

In this study, we aim to assess the preference of the peripheral olfactometry system of $F$. occidentalis towards volatile compounds that are ubiquitously expressed in the plant kingdom. We further aim to establish whether particular enantiomeric or geometric isomers of electrophysiologically active compounds induce greater antennal outputs in comparison to their isomeric counterparts. Such knowledge will aid future research of chemoreception in highly polyphagous insects.

\section{Materials and methods}

\section{Insects}

A colony of $F$. occidentalis, kindly provided by Keele University, UK, was maintained on a bouquet of mixed cultivar chrysanthemum, Dendranthema grandiflora, potted in multi-purpose growing media (to allow for pupation of thrips), and kept on capillary matting inside ventilated Perspex cages (L $30 \mathrm{~cm} \times \mathrm{W} 30 \mathrm{~cm} \times \mathrm{H} 60 \mathrm{~cm}$ ) at $25 \pm 2{ }^{\circ} \mathrm{C}$ and L18: D6 photoperiod. The capillary matting was kept damp with distilled water. A fresh bouquet was placed in the rearing chamber every week, such that three bouquets were present in the rearing chamber at any one time. The oldest bouquet was removed upon addition of a new bouquet; this cycle provided optimal rearing conditions.

\section{Chemicals}

The purities and source of the chemicals used in this study are listed in Table 1. The stereoisomeric configurations of each compound are illustrated in Fig. 1.

\section{Electrophysiological recordings}

Electroantennograms (EAGs) of the antennae of $F$. occidentalis were adapted from a previous method that yielded good EAG recordings from thrips (Abdullah et al. 2014). The anterior portion of an adult female $F$. occidentalis was excised at the groove at which the mesonotum connects to the pronotum, and both antennae excised at the groove between antennal segments 7-8 (most distal to the head) to allow for better contact with the electrodes. The preparation was mounted by placing the proximal (head) end into the reference electrode and both antennae into the recording electrode using micromanipulators. The glass electrodes were filled with glucose-free Ringer's solution (Maddrell 1969). Authentic standards were diluted in mineral oil (Sigma Aldrich; $1: 100 \mathrm{v} / \mathrm{v})$, and applied to strips of filter paper at a dose of $10 \mu \mathrm{l}$. A filter paper was placed in a disposable glass Pasteur pipet and allowed to sit for at least a minute to allow a constant release rate. The pipet was then attached to a $5 \mathrm{ml}$ syringe via rubber tubing. The syringe plunger was depressed (over less than $2 \mathrm{~s}$ ), expelling the volatile contents of the pipet into a purified airstream at a flow of $11 / \mathrm{min}$ through a glass tube (i.d. $120 \mathrm{~mm}$ ) over the preparation. Separate syringes were used for each chemical. The EAG equipment consisted of a $10 \times$ gain universal probe (Syntech, Netherlands) and an IDAC 2 Signal Acquisition Processor (Syntech). 1,8-cineole

Table 1 Source and purities of authentic chemical standards

\begin{tabular}{lll}
\hline Chemical & Source & Purity \\
\hline Mineral oil (light oil) & Sigma Aldrich & $\begin{array}{l}\text { Bioreagent, for molecular } \\
\text { biology }\end{array}$ \\
1,8-cineole (eucalyptol) & Sigma Aldrich & $\geq 99.0 \%(\mathrm{GC})$ \\
Cis-3-hexen-1-ol & Sigma Aldrich & $>98 \%$ \\
Trans-3-hexen-1-ol & Sigma Aldrich $98 \%$ \\
(R)-Limonene & Sigma Aldrich $97 \%$ \\
$($ S)-Limonene & Sigma Aldrich & $\geq 95 \%$ \\
(+)-Terpinen-4-ol & Sigma Aldrich & Analytical standard \\
(-)-Terpinen-4-ol & Sigma Aldrich & $\geq 95.0 \%$ \\
(+)-Borneol & Sigma Aldrich & $97 \%$ \\
(-)-Borneol & Sigma Aldrich & Analytical standard \\
\hline
\end{tabular}




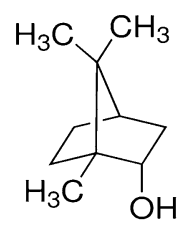

$(+)$

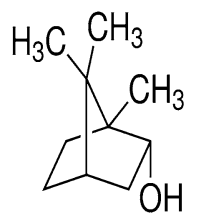

$(-)$

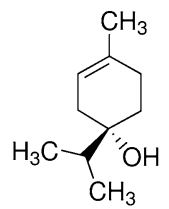

$(+)$

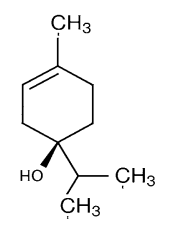

$(-)$ borneol

terpinen-4-ol<smiles>CC/C=C\CCO</smiles><smiles>CC/C=C/CCO</smiles>

trans

3-hexen-1-ol<smiles>C=C(C)[C@H]1CC=C(C)CC1</smiles>

(R)-(+)<smiles>C=C(C)[C@H]1CC=C(C)CC1</smiles>

(S)-(-)

limonene

Fig. 1 Chemical structures of some of the odour compounds used in this study. Cis and trans-3-hexen-1-ol are green leaf volatiles. Both $(R)$ and $(S)$-limonene are monocyclic monoterpenes. (+) and (-)terpinen-4-ol are also monocyclic monoterpenes. $(+)$ and $(-)$-borneol are bicyclic monoterpenes

standard was tested at the start of each replicate and these responses were used to normalize all test recordings to the largest response to the standard recorded in the experiment. To ensure that the amount of standard did not vary through the course of a block recording, a fresh standard preparation was tested at the end to ensure that EAG standard peaks were consistent in size. Responses to a mineral oil control were measured at the start and end of each preparation; these were normalized and then averaged for each block replicate. Fifteen recordings were made to each test compound using a minimum of five insects, recording three replicates per insect.

\section{Data and statistical analyses}

Data were analysed with EAGPro Version 2 software, (Syntech). Data were square root transformed to obtain homogeneity of variance, and analysed using ANOVA. The model incorporated fixed effects of treatment, with both the day and the insect specimen used for each recording included as random factors. Means were compared using a Tukey post hoc test with SPSS software (IBM Corporation, USA).

\section{Results}

Response of antennae to individual plant compounds

For representative EAG responses to each treatment, see Supplementary Fig. 1a-j. All chemicals evoked a significant electrophysiological response $(F(8,121)=91.796$, $p<0.001$ ) compared to the mineral oil control (Fig. 2). The highest depolarisations recorded were towards the green leaf volatiles (GLVs) cis-3-hexen-1-ol $(M=553 \mu \mathrm{V}$, $\mathrm{SD}=13)$ and trans-3-hexen-1-ol $(M=463 \mu \mathrm{V}, \mathrm{SD}=13)$. The depolarizations for the following compounds were: $(R)$-limonene $\quad(M=255 \mu \mathrm{V}, \quad \mathrm{SD}=13), \quad(S)$-limonene $(M=231 \mu \mathrm{V}, \mathrm{SD}=13),(+)$-terpinen-4-ol $(M=270 \mu \mathrm{V}$, $\mathrm{SD}=13), \quad(-)$-terpinen-4-ol $(M=259 \mu \mathrm{V}, \quad \mathrm{SD}=13)$, $(+)$-borneol $(M=239 \mu \mathrm{V}, \quad \mathrm{SD}=13)$ and $(-)$-borneol $(M=251 \mu \mathrm{V}, \mathrm{SD}=13)$. These compounds all produced similar mean EAG depolarisations that were significantly larger than the depolarisations attributable to the mineral oil control treatment $(M=146 \mu \mathrm{V}, \mathrm{SD}=13)(F(8,121)=$ 91.796, $p<0.001)$ but significantly lower than the GLVs cis-3-hexen-1-ol and trans-3-hexen-1-ol $(F(8,121)=$ 91.796, $p<0.001)$.

Capability of antennae to distinguish stereoisomers

Between the two geometric isomers, the compound cis-3hexen-1-ol induced an antennal response that was significantly greater $(F(8,121)=91.796, p=0.003)$ than trans3-hexen-1-ol. Between enantiomers, there was no significant difference between $(R)$-limonene and $(S)$-limonene $(F(8,121)=91.796, p=0.829),(+)$-terpinen-4-ol and $(-$ )-terpinen-4-ol $(F(8,121)=91.796, p=0.999)$ or $(+)$ borneol and $(-)$-borneol $(F(8,121)=91.796, p=0.996)$.

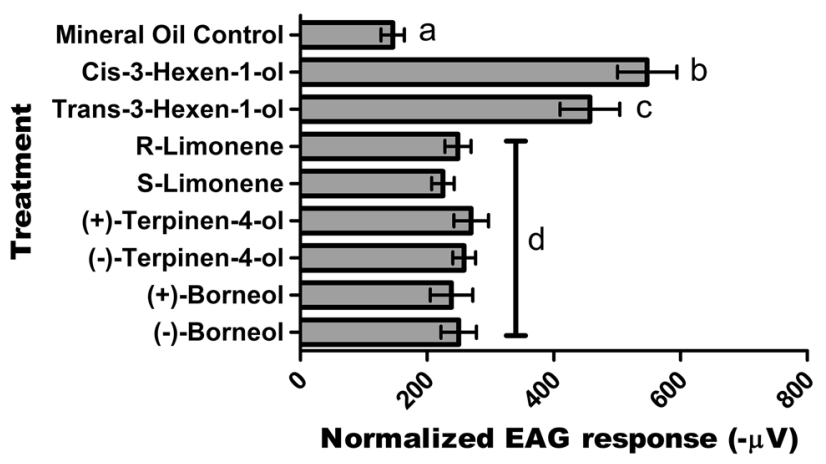

Fig. 2 Mean electroantennogram (EAG) responses (normalized to 1,8-cineole) of adult female western flower thrips to stereoisomeric compounds $(N=15)$ (data presented as mean $\pm 95 \% \mathrm{CI}$, with different letters representing samples that are significantly different; general linear model, Tukey post hoc test) 


\section{Discussion}

The largest mean depolarisation of $F$. occidentalis antennae was towards the GLVs cis-3-hexen-1-ol and trans-3hexen-1-ol. GLVs are formed as a result of oxidative degradation of plant epicuticular waxes and are linked with host recognition via olfactory processes in phytophagous insects from a range of different orders (Visser 1983; Rajapakse et al. 2006; Bruce and Pickett 2011). Cis-3-hexen1-ol induced a significantly larger mean EAG response in thrips compared to its geometric isomer trans-3-hexen-1ol. Cis-3-hexen-1-ol is formed via the reduction of cis-3hexenal, the isomerisation of which leads to the formation of trans-3-hexen-1-ol. The trans configuration is, therefore, less abundant in the emissions of either intact or wounded plants than the cis isomer (Matsui et al. 2012). Hence, from an evolutionary standpoint, a greater abundance of olfactory receptors better tuned to host volatiles of the more profuse geometric isomer would increase success of host seeking. This may explain the significantly larger mean EAG response to cis-3-hexen-1-ol.

Whilst there was a significant mean antennal EAG response of $F$. occidentalis towards all enantiomers of limonene, borneol or terpinen-4-ol compared to the mineral oil control, no significant difference was observed between enantiomers of each particular compound. There was a trend for $(R)$-limonene to produce a slight larger mean depolarisation compared to $(S)$-limonene, a trend that was also seen in previous work done on the parasitic wasp, Microplitis croceipes as well as the Coleopteran insects Anthonomus grandis, Hylastinus obscures and Aegorhinus superciliosus (Park et al. 2001; Palma et al. 2012; Dickens 1984; Mutis et al. 2010). The significant mean antennal EAG response of $F$. occidentalis towards (-)-borneol corroborates previous work; however, the same study found (-)-terpinen-4-ol to evoke a general EAG response that was not significantly different from the control (Abdullah et al. 2014). This may be explained by the fact that the aforementioned study used hexane as a control, which evoked more of an antennal response in $F$. occidentalis (presumably due to non-specific binding of receptors) than the mineral oil control treatment used in this study. All three enantiomeric compounds tested are ubiquitously expressed in the odour bouquet of a wide range of different plants (Williams and Whitten 1983; Borg-Karlson et al. 1987; Brunke et al. 1992; Dobson et al. 1997; Baser 2002; Flamini et al. 2002; Hadacek and Weber 2002), many of which $F$. occidentalis utilize as hosts (Yudin et al. 1986).

In conclusion, we have shown that the peripheral olfactory system of a highly polyphagous thysanopteran insect has evolved to become highly sensitive to a type of green leaf volatile, plant compounds that are highly ubiquitous in the plant kingdom. We have shown that there is a significantly greater antennal response to the cis isomer, more so than the isomerisation by-product trans-3-hexen1-ol. Only further studies utilizing single cell recordings would determine the exact mechanisms that account for this response, such as whether the same ORNs are responding to both odours but with different sensitivity, or whether there are more ORNs of a certain type that binds the cis-3-hexen-1-ol. We demonstrate that the antennae of a highly polyphagous insect contain an array of ORNs capable of detecting common plant secondary metabolites in both enantiomeric forms.

As stereoisomeric compounds are common in many plant species, it would be interesting to know the stereoselectivity of $F$. occidentalis antennae towards even more plant compounds. Furthermore, it would be of great interest to test the antennal responses of highly polyphagous insects from different genera, families and orders against the common plant stereoisomers used in this study. This information would enhance our understanding of stereoselectivity at the peripheral olfactory level, thus aiding the development of more efficient lures or repellents that could be incorporated into integrated pest management systems against highly polyphagous insect pests.

Acknowledgments This work was supported by the Welsh European Funding Office, European Social Fund [Grant number 80300]. Western Flower Thrips were kindly provided by Dr. William Kirk of Keele University. We thank Dr. Christine Woodcock, Professor David Hall, Dr. Ben Webster and Dr. François Verheggen for assistance with EAGs.

Open Access This article is distributed under the terms of the Creative Commons Attribution License which permits any use, distribution, and reproduction in any medium, provided the original author(s) and the source are credited.

\section{References}

Abdullah ZS, Ficken KJ, Greenfield BPJ, Butt TM (2014) Innate responses to putative ancestral hosts: is the attraction of western flower thrips to pine pollen a result of relict olfactory receptors? J Chem Ecol 40(6):534-540

Baser KHC (2002) Aromatic biodiversity among the flowering plant taxa of Turkey. Pure Appl Chem 74:527-545

Bielza P (2008) Insecticide resistance management strategies against the western flower thrips, Frankliniella occidentalis. Pest Manag Sci 64:1131-1138

Bielza P, Quinoto V, Contreras J, Torne M, Martin A, Espinosa PJ (2007) Resistance to spinosad in the western flower thrips, Frankliniella occidentalis (Pergande), in greenhouses of southeastern Spain. Pest Manag Sci 63:682-687

Borg-Karlson A-K, Bergström G, Kullenberg B (1987) Chemical basis for the relationship between Ophrys orchids and their pollinators. II Volatile compounds of $O$. insectifera and $O$. speculum as insect mimetic attractants/excitants. Chemica Scripta 27:303-311 
Bruce TJA, Pickett JA (2011) Perception of plant volatile blends by herbivorous insects-finding the right mix. Phytochemistry 72(13): 1605-1611

Brunke E-J, Hammerschmidt F-J, Schmaus G (1992) Scent of rosesrecent results. Flavour Fragr J 7:195-198

Dethier VG (1947) Chemical insect attractants and repellents. Blakiston, Philadelphia, p 289

Dickens J (1984) Olfaction in the boll weevil, Anthonomus grandis Boh. (Coleoptera: Curculionidae): electroantennogram studies. J Chem Ecol 10:1759-1785

Distler PG, Boeckh J (1996) Synaptic connection between olfactory receptor cells and uniglomerular projection neurons in the antennal lobe of the American cockroach Periplaneta americana. J Comp Neurol 370:35-46

Dobson HEM, Arroyo J, Bergström G, Groth I (1997) Interspecific variation in floral fragrances within the genus Narcissus (Amaryllidaceae). Biochem Syst Ecol 25:685-706

EEC (2009) Directive 2009/128/EC of the European Parliament and of the council of 21 October 2009, establishing a framework for community action to achieve the sustainable use of pesticides. Off J Eur Union L 309:71

Flamini G, Cioni PL, Morelli I (2002) Differences in the fragrances of pollen and different floral parts of male and female flowers of Laurus nobilis. J Agric Food Chem 50:4647-4652

Galizia CG, Rössler W (2010) Parallel olfactory systems in insects: anatomy and function. Annu Rev Entomol 55:399-420

Hadacek F, Weber M (2002) Club-shaped organs as additional osmophores within the Sauromatum inflorescence: odour analysis, ultrastructural changes and pollination aspects. Plant Biol 4:367-383

Kiritani K (2001) Formation of exotic insect fauna in Japan. In: Yano E, Matsuo K, Shiyomi M, Andow DA (eds) Biological invasions of ecosystem by pests and beneficial organisms. Proceedings of an international workshop on biological invasions of ecosystems by pests and beneficial organisms, Tsukuba, 25-27 Feb 1997, pp 49-65

Kirk WDJ (2002) The pest and vector from the west: Frankliniella occidentalis. In: Marullo R, Mound LA (eds) Thrips and tospoviruses. Proceedings of the seventh international symposium on thysanoptera. Australian national insect collection, Canberra, pp 33-44

Kirk WDJ, Terry LI (2003) The spread of the western flower thrips Frankliniella occidentalis (Pergande). Agric For Entomol 5(4):301-310

Laska M, Galizia CG (2001) Enantioselectivity of odor perception in honeybees (Apis mellifera carnica). Behav Neurosci 115: 632-639

Laska M, Teubner P (1999) Olfactory discrimination ability of human subjects to ten pairs of enantiomers. Chem Senses 24:161-170

Leal WS (1996) Chemical communication in scarab beetles: reciprocal behavioural agonist-antagonist activities of chiral pheromones. Proc Natl Acad Sci 93:12112-12115

Linster C, Johnson BA, Yue E, Morse A, Xu Z, Hingco EE, Choi Y, Choi M, Messiha A, Leon M (2001) Perceptual correlates of neural representations evoked by odorant enantiomers. J Neurosci 21:9837-9843

Maddrell SHP (1969) Secretion by the malpighian tubules of Rhodnius. The movement of ions and water. J Exp Biol 51:71-97

Matsui K, Sugimoto K, Mano J, Ozawa R, Takabayashi J (2012) Differential metabolisms of green leaf volatiles in injured and intact parts of a wounded leaf meet distinct ecophysiological requirements. PLoS One 7(4):e36433

Mori K (1998) Chirality and insect pheromones. Chirality 10:578-586

Mori K (2002) Chirality in the natural world: chemical communications. In: Lough WJ, Wainer JW (eds) Chirality in natural and applied science. Blackwell, Oxford, pp 241-259

Morse JG, Hoddle MS (2006) Invasion biology of thrips. Annu Rev Entomol 51:67-89

Mutis A, Parra L, Manosalva L, Palma R, Candia O, Lizama M, Pardo F, Perich F, Quiroz A (2010) Electroantennographic and behavioral responses of adults of raspberry weevil Aegorhinus superciliosus (Coleoptera: Curculionidae) to odors released from conspecific females. Environ Entomol 39:1276-1282

Palma R, Mutis A, Manosalva L, Ceballos R, Quiroz A (2012) Behavioral and electrophysiological responses of Hylastinus obscurus to volatiles released from the roots of Trifolium pratense (L.). J Soil Sci Plant Nutr 12:183-193

Park KC, Zhu JW, Harris J, Ochieng SA, Baker TC (2001) Electroantennogram responses of a parasitic wasp, Microplitis croceipes, to host-related volatile and anthropogenic compounds. Physiol Entomol 26:69-77

Rajapakse CNK, Walter GH, Moore CJ, Hull CD, Cribb BW (2006) Host recognition by a polyphagous lepidopteran (Helicoverpa armigera): primary host plants, host produced volatiles and neurosensory stimulation. Physiol Entomol 31:270-277

Schorkopf DLP, Mitko L, Eltz T (2011) Enantioselective preference and high antennal sensitivity for (-)-ipsdienol in scent-collecting male orchid bees, Euglossa cyanura. J Chem Ecol 37:953-960

Stranden M, Borg-Karlson A-K, Mustaparta H (2002) Receptor neuron discrimination of the germacrene $\mathrm{D}$ enantiomers in the moth Helicoverpa armigera. Chem Senses 27:143-152

Stranden M, Liblikas I, König WA, Almaas TJ, Borg-Karlson A-K, Mustaparta H (2003) (-)-Germacrene D receptor neurons in three species of heliothine moths: structure-activity relationships. J Comp Physiol A 189:563-577

Tolbert LP, Hildebrand JG (1981) Organization and synaptic ultrastructure of glomeruli in the antennal lobes of the moth Manduca sexta: a study using thin sections and freeze-fracture. Proc R Soc B Biol Sci 213:279-301

Tumlinson JH, Klein MG, Doolittle RE, Ladd TL, Proveaux AT (1977) Identification of the female Japanese beetle sex pheromone: inhibition of male response by an enantiomer. Science 197:789-792

Visser JH (1983) Differential sensory perceptions of plant compounds by insects. In: Hedin PA (ed) Plant resistance to insects. ACS symposium series. American Chemical Society, Washington DC, pp 215-230

Wibe A, Borg-Karlson A-K, Persson M, Norin T, Mustaparta H (1998) Enantiomeric composition of monoterpene hydrocarbons in some conifers and receptor neuron discrimination of $\alpha$-pinene and limonene enantiomers in the pine weevil, Hylobius abietis. J Chem Ecol 24:273-287

Williams NH, Whitten WM (1983) Orchid floral fragrances and male euglossine bees: methods and advances in the last sesquidecade. Biol Bull 164:355-395

Yudin LS, Cho JJ, Mitchell WC (1986) Host range of western flower thrips, Frankliniella occidentalis (Thysanoptera: Thripidae), with special references to Leucaena glauca. Environ Entomol 15(6):1292-1295 